\title{
Electrical storm reveals worse prognosis compared to myocardial infarction complicated by ventricular tachyarrhythmias in ICD recipients
}

\author{
Julian Müller ${ }^{1} \cdot$ Michael Behnes $^{1} \mathbb{D} \cdot$ Tobias Schupp $^{1} \cdot$ Dominik Ellguth $^{1} \cdot$ Gabriel Taton $^{1} \cdot$ Linda Reiser $^{1}$. \\ Niko Engelke ${ }^{1} \cdot$ Martin Borggrefe ${ }^{1} \cdot$ Thomas Reichelt $^{1} \cdot$ Armin Bollow $^{1} \cdot$ Ibrahim El-Battrawy $^{1} \cdot$ Kathrin Weidner $^{1}$. \\ Seung-Hyun Kim ${ }^{1}$. Christian Barth ${ }^{1}$. Uzair Ansari ${ }^{1}$ - Dirk Große Meininghaus ${ }^{2} \cdot$ Muharrem Akin $^{3}$. \\ Kambis Mashayekhi ${ }^{4}$ Ibrahim Akin ${ }^{1}$
}

Received: 5 November 2020 / Accepted: 2 April 2021 / Published online: 26 April 2021

(c) The Author(s) 2021

\begin{abstract}
Both acute myocardial infarction complicated by ventricular tachyarrhythmias (AMI-VTA) and electrical storm (ES) represent life-threatening clinical conditions. However, a direct comparison of both sub-groups regarding prognostic endpoints has never been investigated. All consecutive implantable cardioverter-defibrillator (ICD) recipients were included retrospectively from 2002 to 2016. Patients with ES apart from AMI (ES) were compared to patients with AMI accompanied by ventricular tachyarrhythmias (AMI-VTA). The primary endpoint was all-cause mortality at 3 years, secondary endpoints were in-hospital mortality, rehospitalization rates and major adverse cardiac event (MACE) at 3 years. A total of 198 consecutive ICD recipients were included (AMI-VTA: 56\%; ST-segment elevation myocardial infarction (STEMI): 22\%; non-ST-segment myocardial infarction (NSTEMI) 78\%; ES: 44\%). ES patients were older and had higher rates of severely reduced left ventricular ejection fraction (LVEF) $<35 \%$. ES was associated with increased all-cause mortality at 3 years (37\% vs. $19 \% ; p=0.001$; hazard ratio $[\mathrm{HR}]=2.242 ; 95 \% \mathrm{CI} 2.291-3.894 ; p=0.004)$ and with increased risk of first cardiac rehospitalization ( $44 \%$ vs. $12 \% ; p=0.001 ; \mathrm{HR}=4.694 ; 95 \% \mathrm{CI} 2.498-8.823 ; p=0.001$ ). This worse prognosis of ES compared to AMI-VTA was still evident after multivariable adjustment (long-term all-cause mortality: HR $=2.504 ; 95 \% \mathrm{CI}$ 1.093-5.739; $p=0.030$; first cardiac rehospitalization: $\mathrm{HR}=2.887 ; 95 \% \mathrm{CI} 1.240-6.720 ; p=0.014)$. In contrast, the rates of MACE ( $40 \%$ vs. $32 \% ; p=0.326$ ) were comparable in both groups. At long-term follow-up of 3 years, ES was associated with higher rates of all-cause mortality and rehospitalization compared to patients with AMI-VTA.
\end{abstract}

Keywords Electrical storm · Acute myocardial infarction · Ventricular tachycardia $\cdot$ Ventricular fibrillation $\cdot$ Acute heart failure $\cdot$ Heart failure $\cdot$ Sudden cardiac death $\cdot$ MACE $\cdot$ Mortality $\cdot$ Hospitalization

\section{Introduction}

Michael Behnes

michael.behnes@umm.de

1 First Department of Medicine, Faculty of Medicine Mannheim, University of Heidelberg, Theodor-Kutzer-Ufer 1-3, 68167 Mannheim, Germany

2 Department of Cardiology, Carl-Thiem-Klinikum Cottbus, Cottbus, Germany

3 Department of Cardiology and Angiology, Hannover Medical School, Hannover, Germany

4 Department of Cardiology and Angiology II, University Heart Center Freiburg, Bad Krozingen, Germany
Both, electrical storm (ES) and acute myocardial infarction complicated by ventricular tachyarrhythmias (AMI-VTA) represent life-threatening clinical conditions. Up to $6 \%$ of acute coronary syndrome (ACS) cases are complicated by ventricular tachyarrhythmias and associated with an unfavorable clinical outcome [1-3]. Irreversible myocardial ischemia alleviates the development of focal and non-focal arrhythmogenic sources degenerating into ventricular tachycardia (VT) or fibrillation (VF) $[4,5]$. Hemodynamic instability due to ventricular tachyarrhythmias is associated with highest mortality. However, these patients are not well-represented in randomized controlled trials and solid data about 
their prognosis is scarce [6]. Nevertheless, late occurrence of ventricular tachyarrhythmias after $\mathrm{MI}$ is associated with worst prognosis [7].

Moreover, cardiomyopathies, myocarditis, electrolyte disorders or channelopathies are well established triggers for ventricular tachyarrhythmias [8]. ES is defined as at least three distinct episodes of sustained VT or VF requiring implantable cardioverter defibrillator (ICD) therapy within $24 \mathrm{~h}$ [9]. ES patients reveal a wide range of symptoms from asymptomatic delivery of anti-tachycardia pacing (ATP) to hemodynamic instability accompanied by multiple ICDrelated shocks. Especially in patients with ICD and heart failure (HF), ES is a rising epidemiological problem [10]. Due to increasing rates of ICD implantation worldwide, the detection and diagnostic confirmation of ES has accelerated [11]. Nowadays, the prevalence of ES in ICD recipients is estimated around $20 \%$, with rates of $4 \%$ in primary preventive and up to $28 \%$ in secondary preventive ICD recipients [10, 12-14]. Potential triggers of ES are new-onset or worsening HF, changes of antiarrhythmic drug therapies, diarrhea, hypokalemia and psychological stress. Furthermore, severe systolic dysfunction, chronic kidney disease and VT as the initial arrhythmia are regarded as independent and established predictors of ES [10, 14].

However, the prognostic impact of both high-risk diseases, i.e. AMI complicated by ventricular tachyarrhythmias (AMI-VTA) and of ES, has never been compared before. Therefore, the present study comparatively evaluates the long-term prognostic impact of AMI-VTA compared to ES independent from AMI in consecutive ICD recipients.

\section{Methods}

\section{Study population}

The present study included all consecutive ICD recipients presenting with AMI-VTA and those with ES apart from AMI presenting from 2002 until 2016 at one institution (Fig. 1).

Ventricular tachyarrhythmias comprised VT and VF, as defined by current international guidelines [6, 8]. VT was classified in the presence of a regular RR interval, large QRS morphology, changing polarity of QRS deflections during tachycardia compared to sinus rhythm and sudden onset of tachycardia. A heart rate $>250 / \mathrm{min}$ with irregular RR intervals classified VF [6, 8]. Ventricular tachyarrhythmias were documented by ICD and in some cases additionally by 12-lead electrocardiogram (ECG), ECG tele-monitoring, or in case of unstable course or during resuscitation by external defibrillator monitoring. Left ventricular ejection fraction (LVEF) was measured prior to discharge by standardized transthoracic echocardiogram after stabilization of ES. To a small extent and only if available, LVEF was assessed bedside on admission or during intensive care in hemodynamically unstable patients with expected death within the acute phase of AMI-VTA or ES already.

All relevant clinical data was documented using the electronic hospital information system, ICD protocols, discharge letters, patients' files, 12-lead ECGs and Holter-ECGs being assessed during clinical routine. In detail, data documentation comprised baseline characteristics, prior medical
Fig. 1 Flow chart of the study population

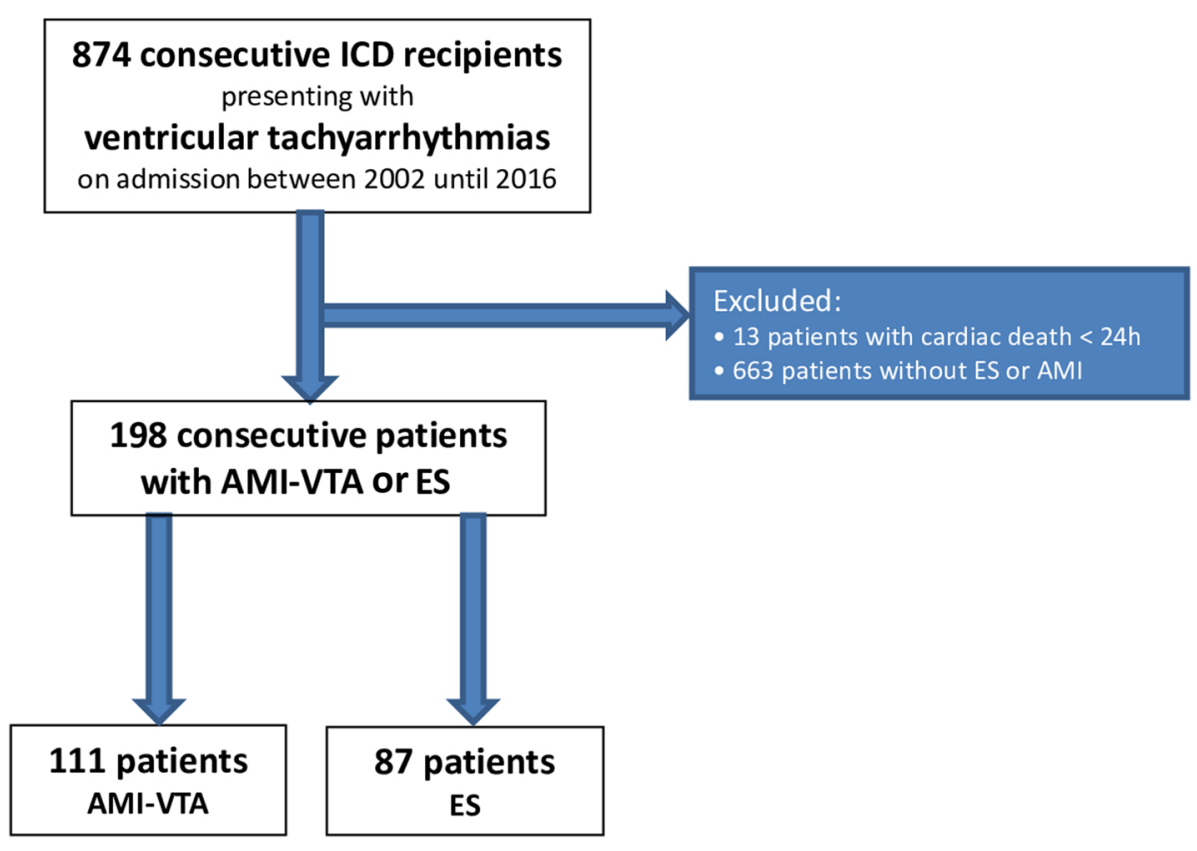


history, prior medical treatment, length of index stay, all findings of laboratory values at baseline, data derived from all non-invasive or invasive cardiac diagnostics and device therapies, such as coronary angiography, electrophysiological examination, as well as imaging modalities, such as echocardiography or cardiac magnetic resonance imaging (cMRI). Documentation period lasted from index event until 2016. Independent cardiologists performed documentation of all medical data blinded to final data analyses.

The present study is derived from an analysis of the " $\underline{\text { Reg- }}$

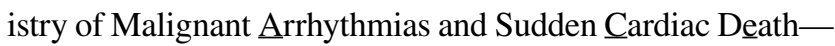
Influence of Diagnostics and Interventions (RACE-IT)" and represents a single-center registry including consecutive patients presenting with ventricular tachyarrhythmias and aborted cardiac arrest (SCD) being acutely admitted to the University Medical Center Mannheim (UMM), Germany (clinicaltrials.gov identifier: NCT02982473) from 2002 until 2016. The registry was carried out according to the principles of the declaration of Helsinki and was approved by the medical ethics committee II of the Faculty of Medicine Mannheim, University of Heidelberg, Germany.

\section{Definition of study groups, inclusion and exclusion criteria}

Patients with AMI-VTA were compared to patients with ES apart from AMI. All patients already had an activated ICD prior to inclusion.

The AMI-VTA group comprised all consecutive ICD recipients presenting with AMI complicated by ventricular tachyarrhythmias during inclusion period. AMI-VTA patients with cardiac death $<24 \mathrm{~h}$ were excluded. AMI was defined according to European guidelines [8, 15-18]. ST-segment-elevation myocardial infarction (STEMI) was defined as a novel rise in the ST segment in two adjacent ECG leads, greater than $2 \mathrm{~mm}(0.2 \mathrm{mV})$ for males and greater than $1.5 \mathrm{~mm}(0.15 \mathrm{mV})$ in females in all leads except for $\mathrm{V} 2$ and $\mathrm{V} 3$, where it must be greater than $1 \mathrm{~mm}$ $(0.1 \mathrm{mV})$. Additional ECG criteria were new ST depression or inversion, $\mathrm{T}$ wave alterations, $\mathrm{Q}$ waves or new left bundle branch block. Non-ST-segment-elevation myocardial infarction (NSTEMI) was defined as the presence of an ACS with a troponin I increase of above the 99th percentile of a healthy reference population. The culprit lesion was defined as an acute complete thrombotic occlusion for STEMI and any relevant critical coronary stenosis for NSTEMI with the potential need for coronary revascularization either by PCI or coronary artery bypass grafting. Target vessel revascularization (TVR) was defined as any percutaneous intervention of the target lesion or bypass surgery of the target vessel performed for stenosis or other complication of the target lesion. The presence of a coronary culprit lesion with the potential need for coronary revascularization either by PCI or CABG was mandatory for both diagnoses of NSTEMI and STEMI. Evidence of regional wall motion abnormalities was also included in AMI diagnosis as far as available.

The ES group comprised all ICD recipients with ES during inclusion period. ES patients with cardiac death $<24 \mathrm{~h}$ were excluded. ES was defined as $\geq 3$ episodes of ventricular tachyarrhythmias delimited by at least 5 min leading to appropriate ICD therapy during a single time period of $24 \mathrm{~h}$.

Patients with cardiac death at $24 \mathrm{~h}$ were excluded. Cardiac death was defined as cardiac death occurring within $24 \mathrm{~h}$ after onset of ventricular tachyarrhythmias (VT or VF) or ES. Furthermore, patients with cardiac death within $24 \mathrm{~h}$ of an assumed unstable cardiac condition leading to cardiac death, such as high degree AV-block, asystole, acute heart failure (AHF), cardiogenic shock or cardiopulmonary resuscitation (CPR) even in the absence of ventricular tachyarrhythmias, were excluded [8]. Each patient was counted only once for inclusion.

\section{Definition of endpoints}

The primary endpoint was all-cause mortality at three years. The observational period for primary and secondary endpoints started with the index presentation at our medical center with ES or AMI-VTA and lasted for 3 years thereafter. Secondary endpoints comprised in-hospital mortality, first rehospitalization and major adverse cardiac events (MACE) both at three years. First rehospitalization comprised first rehospitalization due to VT, VF, CPR, AHF, AMI, inappropriate ICD shock or stroke at 3 years of follow-up. MACE were defined as the composite of AMI, target vessel revascularization (TVR) by percutaneous coronary intervention (PCI) or coronary artery bypass grafting (CABG) and all-cause mortality [19].

All-cause mortality was documented using our electronic hospital information system and by directly contacting state resident registration offices ("bureau of mortality statistics") across Germany. Identification of patients was verified by name, surname, date of birth and registered living address.

\section{Statistical methods}

Quantitative data is presented as mean \pm standard error of mean (SEM), median and interquartile range (IQR) and ranges depending on the distribution of the data. It was compared using the student's $t$ test for normally distributed data or the Mann-Whitney $U$ test for non-parametric data. Deviation from a Gaussian distribution were tested by the Kolmogorov-Smirnov test. Spearman's rank correlation for non-parametric data was used to test univariate correlations. 
Qualitative data are presented as absolute and relative frequencies and compared using the $\mathrm{Chi}^{2}$ test or the Fisher's exact test, as appropriate.

The following analyses were applied stepwise to evaluate the prognostic value of predefined variables for all-cause mortality: Kaplan-Meier survival curves were calculated with log-rank testing for statistical significance. Uni-variable hazard ratios (HR) are given together with $95 \%$ confidence intervals. Multivariable Cox regression models with allcause mortality and rehospitalization as the dependent variable were developed using the "forward selection" option. Multivariable models were adjusted both by univariably statistically significant variables such as treatment with statin or amiodarone and impaired LVEF $(p<0.05)$, as well as with clinically relevant variables such as age, diabetes, chronic kidney disease (CKD) and coronary artery disease (CAD).

The result of a statistical test was considered significant for $p<0.050$, and a statistical trend was defined as $p<0.100$. SPSS (Version 25, IBM Armonk, New York, USA) was used for statistics.

\section{Results}

\section{Study population}

A total of 198 consecutive ICD recipients were included, of which $44 \%$ suffered from at least one episode of ES and $56 \%$ from AMI-VTA (Fig. 1).

As illustrated in Table 1, most patients were males (at least $82 \%$ ). ES patients were older (70 years vs. 66 years; $p=0.026)$; whereas AMI-VTA patients presented with significantly higher rates of smoking (38\% vs. $17 \%$; $p=0.001)$ and cardiac family history (20\% vs. $8 \%$; $p=0.020)$. Other cardiovascular risk factors were comparable between both groups. However, AMI-VTA patients suffered from cardiogenic shock (20\% vs. $2 \% ; p=0.001)$ and underwent CPR (52\% vs. 6\%; $p=0.001)$ more often. In contrast, dilated cardiomyopathy (DCM) (16\% vs. $0 \%$; $p=0.001$ ) was more common in ES patients. In addition, ablation therapy due to VT was more often performed in ES patients (21\% vs. $5 \% ; p=0.001)$.

AMI-VTA patients were treated more often with statins $(93 \%$ vs. $60 \%$; $p=0.001)$, ES patients more often treated with amiodarone (54\% vs. $20 \% ; p=0.001)$. The ECG recorded at baseline showed significantly longer PQ $(220 \mathrm{~ms} \pm 11 \mathrm{~ms}$ vs. $179 \mathrm{~ms} \pm 8 \mathrm{~ms} ; p=0.005)$ and QT intervals (440 ms $\pm 14 \mathrm{~ms}$ vs. $410 \mathrm{~ms} \pm 16 \mathrm{~ms}, p=0.033$ ) in ES patients. In addition, ES patients suffered more often from severely reduced LVEF (69\% vs. 44\%; $p=0.008$ ) (Table 1).

The most common device was a conventional ICD (89\% vs. $87 \%$ ), followed by transvenous CRT-D (7 vs. $9 \%$ ) and subcutaneous ICD (4\% vs. 3\%). Those devices were mostly implanted for secondary prevention (65\% vs. 63\%) (Table 1).

\section{Distribution of CAD and VTA in both groups}

Within AMI-VTA patients, STEMI was less common than NSTEMI (22\% vs. 78\%). AMI was more often complicated by VF than VT ( $52 \%$ vs. $48 \%$ ) and infarct-related VT occurred three times more often $<48 \mathrm{~h}$ than $>48 \mathrm{~h}$ post AMI (34\% vs. 14\%). AMI-VTA patients underwent coronary angiography more often ( $88 \%$ vs. $52 \% ; p=0.001)$. CAD was significantly more common in AMI-VTA patients $(87 \%$ vs. $44 \% ; p=0.001)$. Coronary single vessel disease was more frequent in AMI-VTA patients (28\% vs. $5 \% ; p=0.009)$; whereas, CABG was more common in ES patients $(24 \%$ vs. $10 \%$; $p=0.011)$. Furthermore, an intracoronary thrombus was more often found in AMI-VTA patients (7\% vs. $0 \%$; $p=0.008$ ) (Table 2 ).

AMI-VTA patients had higher rates of PCI during index coronary angiography (69\% vs. $16 \% ; p=0.001)$. Among AMI-VTA patients, TVR was more often performed in the right coronary artery $(23 \%$ vs. $5 \% ; 0.001)$, left anterior descending artery $(41 \%$ vs. $8 \% ; p=0.001)$ and left circumflex artery ( $18 \%$ vs. $7 \% ; p=0.033)$; whereas, ES patients had TVR more often at the left main trunk $(5 \%$ vs. $0 \% ; p=0.036$ ) (Table 2).

\section{Primary endpoint of long-term all-cause mortality}

At three years of long-term follow-up (mean 35 months) starting with index event of ES or AMI-VTA at presentation in our medical center, ES was associated with higher rates of all-cause mortality compared to AMI-VTA patients (37\% vs. $19 \%$, log rank $p=0.003$; Table 3; Fig. 2, left panel), corresponding to a 2.2-fold increased risk of all-cause death (HR 2.242; 95\% CI 1.291-3.894, $p=0.004)$. Consistently, allcause mortality of ES patients remained even higher when only ES patients with ischemic heart disease were compared with AMI-VTA patients (49\% vs. $19 \%, \log \operatorname{rank} p=0.014$, data not shown).

Furthermore, ES patients still remained at highest risk for mortality when AMI patients with occurrence of ventricular tachyarrhythmias $<48 \mathrm{~h}$ after AMI were excluded from the AMI-VTA group within this analysis (37\% vs. $25 \%, \log$ rank $p=0.039$, data not shown).

\section{Secondary endpoints}

No differences were observed regarding in-hospital mortality in between ES and AMI-VTA patients (2\% vs. 5\%; $p=0.404)$. In contrast, ES patients revealed significantly higher rates of overall first cardiac rehospitalization (44\% vs. 


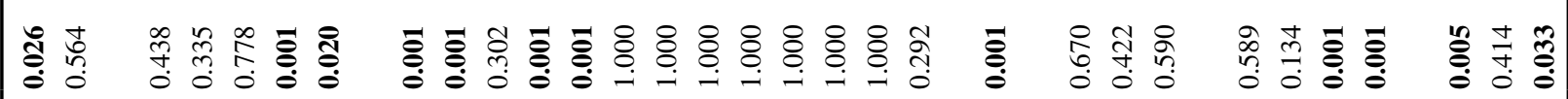

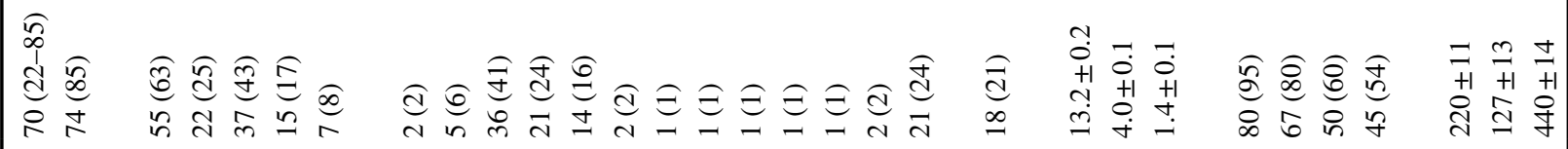

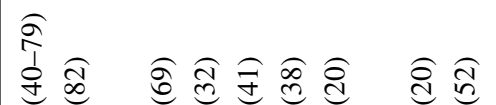

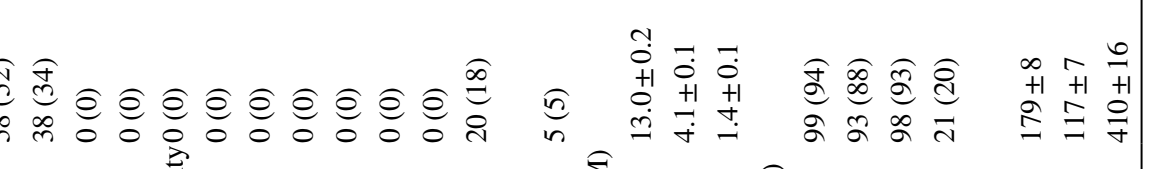

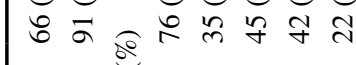

: 离

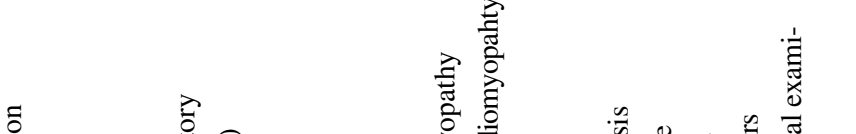

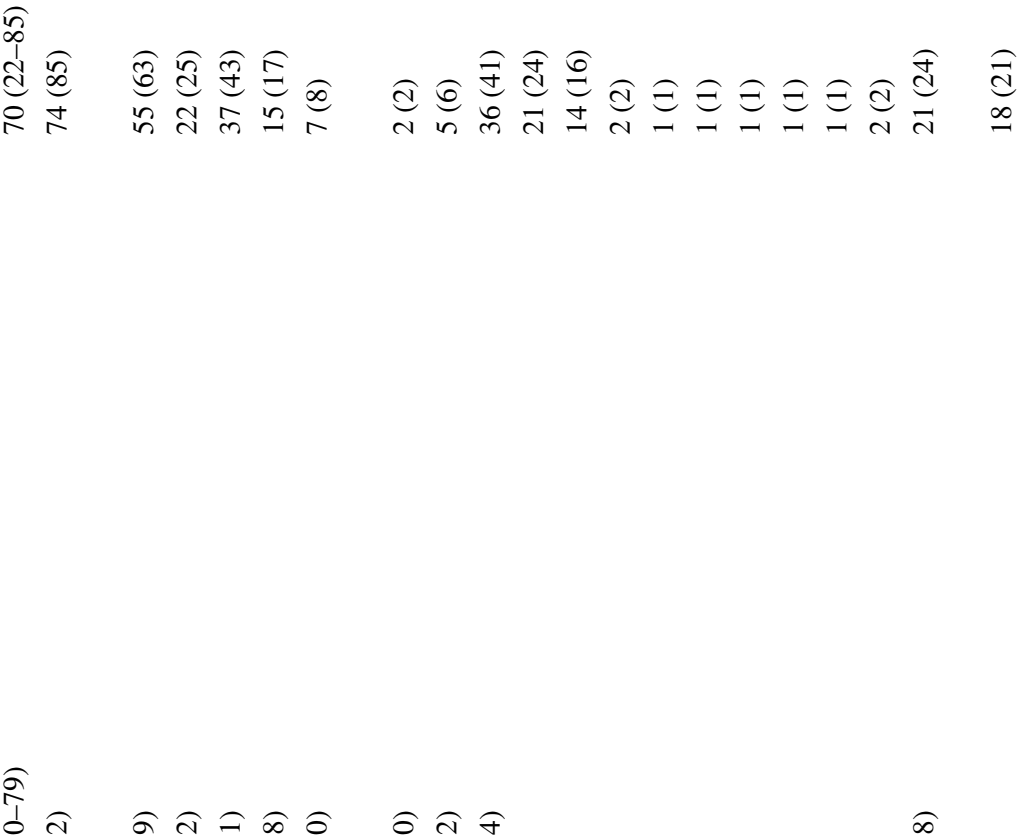

$\sum_{\text {空 }}^{\widehat{n}}$

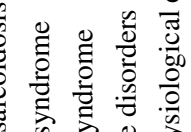

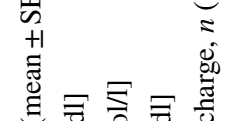

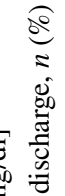




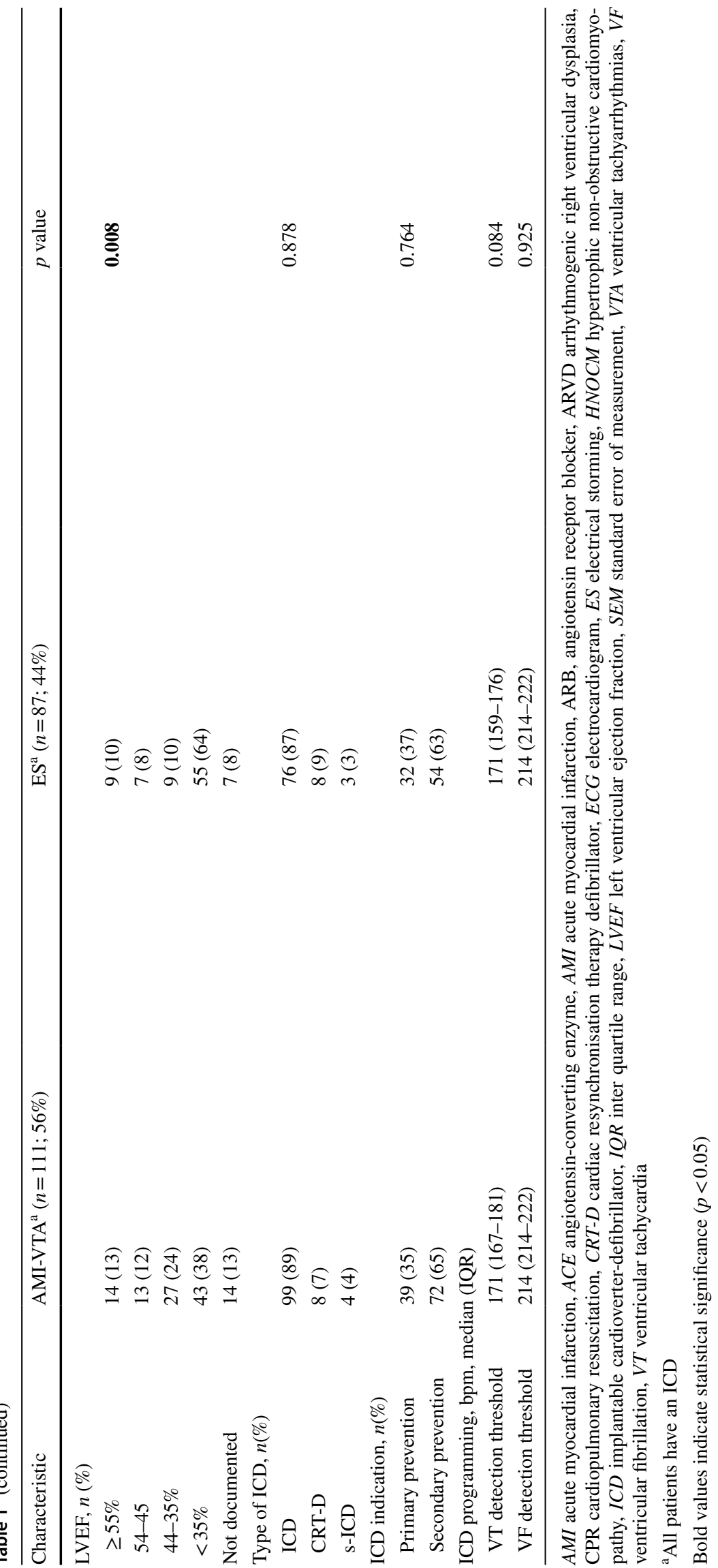


Table 2 Characteristics of coronary artery disease in between AMIVTA and ES

\begin{tabular}{llllll}
\hline & AMI- & \multicolumn{2}{l}{ ES $^{\mathrm{a}}$} & $p$ value \\
& VTA $^{\mathrm{a}}$ & $(n=87 ;$ & \\
& $(n=111 ;$ & $44 \%)$ & \\
& $56 \%)$ & & & \\
\hline STEMI & 24 & $(22)$ & 0 & $(0)$ & $\mathbf{0 . 0 0 1}$ \\
NSTEMI & 87 & $(78)$ & 0 & $(0)$ & $\mathbf{0 . 0 0 1}$ \\
With VT & 53 & $(48)$ & - & - & - \\
VT $<48$ h & 38 & $(34)$ & - & - & - \\
VT $>48$ h & 15 & $(14)$ & - & - & - \\
With VF & 58 & $(52)$ & - & - & - \\
Coronary angiography, overall & 98 & $(88)$ & 45 & $(52)$ & $\mathbf{0 . 0 0 1}$ \\
Coronary artery disease & 96 & $(87)$ & 38 & $(44)$ & $\mathbf{0 . 0 0 1}$ \\
No evidence of CAD & 2 & $(2)$ & 7 & $(8)$ & $\mathbf{0 . 0 0 1}$ \\
1-vessel & 28 & $(28)$ & 4 & $(5)$ & $\mathbf{0 . 0 0 9}$ \\
2-vessel & 32 & $(33)$ & 10 & $(11)$ & 0.239 \\
3-vessel & 36 & $(37)$ & 24 & $(28)$ & 0.070 \\
Prior CABG & 11 & $(10)$ & 21 & $(24)$ & $\mathbf{0 . 0 1 1}$ \\
Intracoronary thrombus & 8 & $(7)$ & 0 & $(0)$ & $\mathbf{0 . 0 0 8}$ \\
CPR during coronary angiography & 6 & $(5)$ & 0 & $(0)$ & 0.069 \\
PCI, $n$ (\%) & 76 & $(69)$ & 14 & $(16)$ & $\mathbf{0 . 0 0 1}$ \\
Target vessel revascularization, $n(\%)$ & & & & \\
RCA & 26 & $(23)$ & 4 & $(5)$ & $\mathbf{0 . 0 0 1}$ \\
LMT & 0 & $(0)$ & 4 & $(5)$ & $\mathbf{0 . 0 3 6}$ \\
LAD & 46 & $(41)$ & 7 & $(8)$ & $\mathbf{0 . 0 0 1}$ \\
LCx & 20 & $(18)$ & 6 & $(7)$ & $\mathbf{0 . 0 3 3}$ \\
RIM & 0 & $(0)$ & 0 & $(0)$ & - \\
Bypass graft & 0 & $(0)$ & 0 & $(0)$ & - \\
Sent to CABG & 0 & $(0)$ & 0 & $(0)$ & - \\
\hline & & & & & \\
& & &
\end{tabular}

$A M I$ acute myocardial infarction, $C A B G$ coronary artery bypass graft, $C A D$ coronary artery disease, $E S$ electrical storming, $I C D$ implantable cardioverter-defibrillator, $L A D$ left anterior descending, $L C x$ left circumflex, LMT left main trunk, NSTEMI non-ST-segment-elevation myocardial infarction, $P C I$ percutaneous coronary intervention, $R C A$ right coronary artery, RIM ramus intermedius, STEMI ST-segmentelevation myocardial infarction, $T V R$ target vessel revascularization, $V F$ ventricular fibrillation, $V T$ ventricular tachycardia, $V T A$ ventricular tachyarrhythmia

${ }^{a}$ All patients had an ICD

Bold values indicate statistical significance $(p<0.05)$

$12 \%$; $\log$ rank $p=0.001)$, mainly attributed to VT $(23 \%$ vs. $0 \% ; p=0.001)$ and AHF (17\% vs. $6 \% ; p=0.010)$. The risk of cardiac rehospitalization for ES patients was 4.7 times higher compared to AMI-VTA patients (HR 4.694, 95\% CI 2.498-8.823; $p=0.001$; Table 3; Fig. 2, middle panel).

Notably, rates of MACE were equally distributed between ES and AMI-VTA patients ( $40 \%$ vs. $32 \% ; p=0.204$; Table 3; Fig. 2, right panel). For most patients all-cause mortality was the reason for MACE. Apart from that, TVR was significantly more often performed in AMI-VTA patients
Table 3 Primary and secondary endpoints

\begin{tabular}{|c|c|c|c|c|c|}
\hline \multirow{2}{*}{$\begin{array}{l}\text { Characteristics } \\
\text { Primary endpoint, } n(\%)\end{array}$} & \multicolumn{2}{|c|}{$\begin{array}{l}\text { AMI-VTA } \\
(n=111 ; \\
56 \%)\end{array}$} & \multicolumn{2}{|c|}{$\begin{array}{l}\mathrm{ES}(n=87 ; \\
44 \%)\end{array}$} & \multirow[t]{2}{*}{$p$ value } \\
\hline & & & & & \\
\hline All-cause mortality & 21 & (19) & 32 & (37) & 0.005 \\
\hline \multicolumn{6}{|l|}{ Secondary endpoints, $n(\%)$} \\
\hline In-hospital mortality & 5 & $(5)$ & 2 & (2) & 0.404 \\
\hline \multicolumn{6}{|l|}{ First rehospitalization } \\
\hline Overall & 13 & (12) & 38 & (44) & 0.001 \\
\hline VT & 0 & $(0)$ & 19 & (23) & 0.001 \\
\hline $\mathrm{VF}$ & 1 & $(0.9)$ & 0 & $(0)$ & 1.000 \\
\hline CPR & 0 & $(0)$ & 2 & (2) & 1.000 \\
\hline Acute heart failure & 6 & (6) & 15 & (17) & 0.010 \\
\hline Acute myocardial infarction & 2 & (2) & 1 & (1) & 1.000 \\
\hline Inappropriate ICD shock & 4 & (4) & 0 & $(0)$ & 1.000 \\
\hline Stroke & 0 & $(0)$ & 1 & (1) & 1.000 \\
\hline MACE & 35 & $(32)$ & 35 & $(40)$ & 0.204 \\
\hline All-cause mortality & 21 & (19) & 32 & (37) & 0.005 \\
\hline AMI & 4 & (4) & 1 & (1) & 0.275 \\
\hline TVR & 15 & (14) & 2 & (2) & 0.005 \\
\hline CABG & - & - & - & - & - \\
\hline
\end{tabular}

$A M I$ acute myocardial infraction, $C A B G$ coronary artery bypass graft, $C P R$ cardiopulmonary resuscitation, ES electrical storming, ICD implantable cardioverter-defibrillator, $M A C E$ major adverse cardiac events, $T V R$ target vessel revascularization, $V F$ ventricular fibrillation, $V T$ ventricular tachycardia, VTA ventricular tachyarrhythmia Bold values indicate statistical significance $(p<0.05)$

during follow-up time. Of note, 23 patients with ES developed recurrences of ES within follow-up (26\%).

\section{Multivariable Cox models}

Increased long-term all-cause mortality in ES patients was still evident after multivariable adjustment (HR 2.504; 95\% CI 1.093-5.739; $p=0.030$ ), besides age (HR 1.042; 95\% CI $1.001-1.085 ; p=0.043)$ and CKD (HR 6.876; 95\% CI 2.602-18.170; $p=0.001$ ) (Table 4). Furthermore, ES was still associated with 2.9-fold increased risk of rehospitalization (HR 2.887; 95\% CI 1.240-6.720; $p=0.014$ ) (Table 5).

\section{Discussion}

The present study evaluates the prognostic impact of AMI complicated by ventricular tachyarrhythmias compared to that of ES apart from AMI on long-term all-cause mortality, as well as rates of rehospitalization and MACE in consecutive ICD recipients. This data suggests that ES is associated with worse long-term prognosis, even when compared to high-risk patients with AMI-VTA and even 

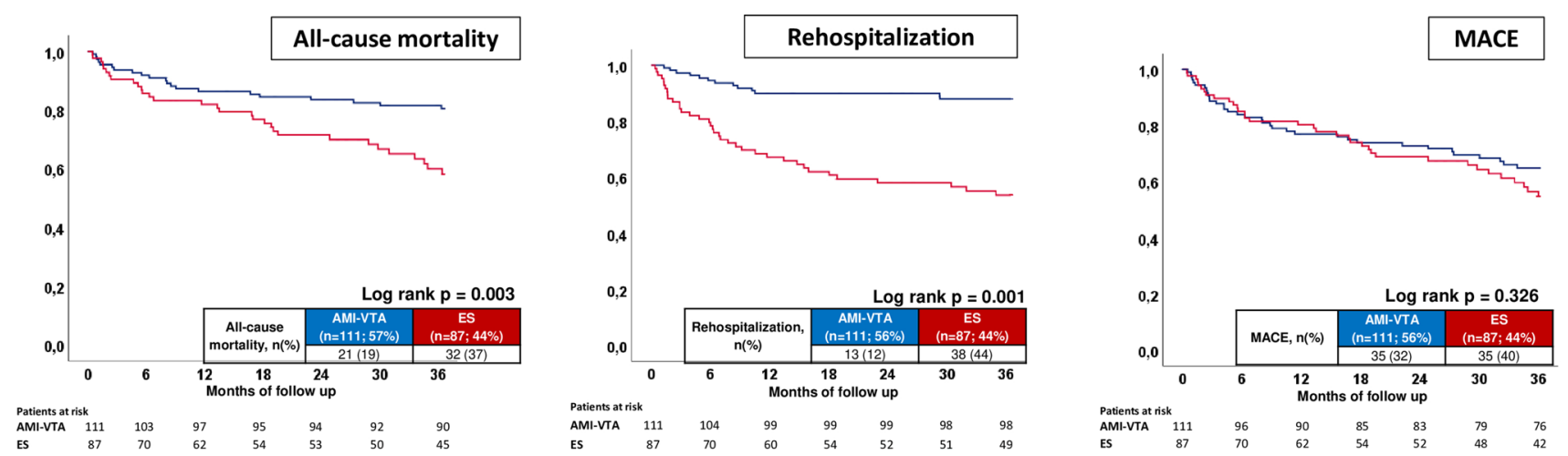

Fig. 2 Prognostic impact of acute myocardial infarction complicated by ventricular tachyarrhythmias (AMI-VTA) compared to electrical storm (ES) on long-term all-cause mortality (left panel), overall rehospitalization (middle panel) and major adverse cardiac events (MACE) (right panel) in implantable cardioverter-defibrillator (ICD) recipients
Table 4 Multivariable Cox regression for long-term all-cause mortality at 2.5 years

\begin{tabular}{llll}
\hline Variable & HR & $95 \%$ CI & $p$ value \\
\hline Age & 1.042 & $1.001-1.085$ & $\mathbf{0 . 0 4 3}$ \\
Diabetes & 1.235 & $0.597-2.555$ & 0.569 \\
Chronic kidney disease & 6.876 & $2.602-18.170$ & $\mathbf{0 . 0 0 1}$ \\
CAD & 1.629 & $0.607-4.370$ & 0.333 \\
Amiodarone treatment & 1.598 & $0.782-3.265$ & 0.198 \\
LVEF $\leq 35 \%$ & 1.180 & $0.753-1.850$ & 0.469 \\
Statin treatment & 0.797 & $0.328-1.935$ & 0.616 \\
Electrical storm & 2.504 & $1.093-5.739$ & $\mathbf{0 . 0 3 0}$ \\
\hline
\end{tabular}

$C A D$ coronary artery disease, $C I$ confidence interval, $H R$ hazard ratio, $L V E F$ left ventricular ejection fraction; Chronic kidney disease defines as creatinine $>1.2 \mathrm{mg} / \mathrm{dl}$

Bold values indicate statistical significance $(p<0.05)$

Table 5 Multivariable Cox regression for long-term rehospitalization at 2.5 years

\begin{tabular}{llll}
\hline Variable & HR & $95 \%$ CI & $p$ value \\
\hline Age & 1.006 & $0.980-1.032$ & 0.667 \\
Diabetes & 0.808 & $0.390-1.671$ & 0.564 \\
Chronic kidney disease & 0.736 & $0.387-1.399$ & 0.349 \\
CAD & 0.692 & $0.312-1.532$ & 0.363 \\
Amiodarone treatment & 1.653 & $0.812-3.365$ & 0.165 \\
LVEF $\leq 35 \%$ & 1.054 & $0.753-1.476$ & 0.757 \\
Statin treatment & 0.593 & $0.285-1.231$ & 0.161 \\
Electrical storm & 2.887 & $1.240-6.720$ & $\mathbf{0 . 0 1 4}$ \\
\hline
\end{tabular}

$C A D$ coronary artery disease, $C I$ confidence interval, $H R$ hazard ratio, $L V E F$ left ventricular ejection fraction; Chronic kidney disease defines as creatinine $>1.2 \mathrm{mg} / \mathrm{dl}$

Bold values indicate statistical significance $(p<0.05)$ in the presence of an activated ICD. ES patients were associated with increased all-cause mortality and rehospitalization rates at 3 years, mainly attributed to recurrent VT and AHF. Worse prognosis in ES patients was still evident after multivariable adjustment.

Despite improvements in device therapies, SCD still occurs in $2 \%$ of all ICD patients. Furthermore, the number of recurrences of VT and VF is directly related to death rates [20]. A recent meta-analysis comparing ES patients to patients without any history of ventricular tachyarrhythmias revealed a 3.1-fold increased risk of all-cause mortality among ES patients. Interestingly, increasing rates of mortality were still evident between ES patients and patients with a history of ventricular tachyarrhythmias apart from ES [21]. However, this meta-analysis included all potential comorbidities triggering ventricular tachyarrhythmias and focused only on the risk of all-cause mortality and the composite endpoint of all-cause mortality, heart transplantation and hospitalization due to HF. In contrast, the present study explicitly included all patients with AMI-VTA. The adverse prognostic impact of ES compared to AMI-VTA was still evident despite the presence of an activated ICD.

Up to $6 \%$ of patients with AMI develop VT or VF during the first $48 \mathrm{~h}$ after onset of ischemia-related symptoms, commonly prior to or during coronary revascularization. Due to better revascularization strategies and preventive measures for CAD the incidence of AMI-VTA has declined in recent decades [8].

Acute myocardial ischemia favors electrical instability provoking ventricular tachyarrhythmias in patients with AMI. During the acute phase of ischemia a multifactorial sequence of events results in ionic imbalance, less reduced resting membrane potential and reduced conduction velocity [22]. One important contributor in arrhythmogenesis is the 
intracellular $\mathrm{Ca}^{2+}$ overload resulting in spontaneous $\mathrm{Ca}^{2+}$ oscillations triggering early and delayed after-depolarizations induced ectopic beats [23]. Whereas, basic macro reentry mechanisms from heterogenous substrates might pose the responsible mechanism for ventricular tachyarrhythmias during ischemia, impulse initiation caused by after-depolarizations appears the dominant mechanism in reperfusion [24].

Within the present study, half of all AMI patients underwent CPR related to ventricular tachyarrhythmias reflecting hemodynamic instability and cardiogenic shock. In contrast, increased antiarrhythmic therapies such as VT ablation and amiodarone treatment were present in patients with ES. Nevertheless, ES patients died significantly more often during follow-up time compared to patients with AMI-VTA. These findings suggest that ES patients, even when compared to a highest-risk cohort of patients with AMI-VTA represent a population of utmost risk for cardiovascular death. Even after exclusion of patients suffering from VTA within $48 \mathrm{~h}$ after AMI ES patients remained at highest for subsequent mortality [3]. Accordingly, this impaired prognosis could be also confirmed in multivariable regression models.

Several pathophysiological hypotheses explaining the increased risk of death among ES patients are available. Some authors revealed an increased mortality rate among patients with ventricular tachyarrhythmias terminated by shocks compared to patients treated only by ATP with or without antiarrhythmic therapy [25]. Recurrent shocks might contribute to transient systolic dysfunction and AHF in terms of cardiac decompensation [26]. Another possible explanation might be that recurrent VT, especially incessant VTs, promote LV dysfunction leading to advanced HF, cardiogenic shock and death [27]. Accordingly, the results of the present study provide further understanding and affirm the hypothesis that ES might affect mortality via LV dysfunction. ES patients presented with more severely decreased LVEF and higher rates of VT recurrences. Presumably, most ES patients died from advanced ischemic heart failure with concomitant CKD. Advanced heart failure per se is a major risk factor for subsequent mortality. In addition, cardiorenal syndrome represents worst prognosis for patients presenting with ventricular tachyarrhythmias $[28,29]$.

Interestingly, in patients with drug-resistant ES, VT ablation provided increased survival rates. Reduction of tachyarrhythmic episodes might prevent associated decline of LVEF. And severely reduced LVEF is considered as the strongest predictor of mortality among ES patients [30, 31].

ES is also associated with increasing rates of rehospitalization alongside with each ICD shock delivery. Baensch et al. revealed a 50\% risk for rehospitalization in patients with $\leq 3$ shocks; whereas, those with more than 3 shocks were hospitalized $100 \%$ of the time [27]. The increased overall rehospitalization rates within this study were specifically related to VT and AHF among ES patients. This observation is in line with recent findings of Guerra et al. proposing ES as a clinical manifestation of worsening HF [21]. Also, the association between increased rehospitalization rates attributed to VT and ES was not unexpected. Monomorphic VT represents often a scar-related re-entry mechanism in the presence of heart failure due to ischemic or structural heart diseases, which can promote and sustain ES in many cases [10]. Occurrence of VT in the setting of heart failure is dependent on systolic dysfunction and within this study ES patients suffered mostly from severely reduced LVEF.

This study demonstrated the adverse prognostic impact of ES compared to AMI-VTA on long-term all-cause mortality and cardiac rehospitalization rates. Therefore, ES patients constitute a population associated with the highest risk of death. Due to this significant prognostic impact, ES patients require close clinical follow-ups and optimal pharmacological HF treatment with beta-blockers and amiodarone, as well as ICD treatment. Furthermore, since the majority of ES originate from a basic re-entry mechanism, catheter ablation is a curative approach to interrupt episodes of ventricular tachycardias. Additionally, ablation was shown to be able to decrease ES burden [30]. Notably, in some cases thoracic epidural anesthesia, renal sympathetic denervation and left cardiac sympathetic denervation are further potential therapeutic options, recently being associated with a decrease in arrhythmic burden [32-34].

In summary, ES represents a pathology with a worse prognosis compared to high-risk patients with AMI-VTA, even in the presence of an activated ICD. Further efforts should be made to unify diagnostic and therapeutic strategies for ES patients, such as invasive VT ablation and coronary angiography. Future prospective multi-center studies are needed to verify further the prognostic impact of CAD and ablation therapy both in AMI-VTA and ES patients.

\section{Study limitations}

The main limitation of this study is the retrospective study design and the rather small sample size. Only all-cause mortality rates were documented, detailed analyses about definite cause of death were beyond the scope of the study. Rehospitalization rates were only documented within our own institution. Patients with prolonged hemodynamic instability and lethal outcome before admission and those not surviving out of hospital CPR without transfer to the heart center were not included in this study. Ablation rates among ES patients were rather low, possibly preventing to show the beneficial effect of ablation. 


\section{Conclusions}

ES is associated with higher long-term all-cause mortality and rehospitalization rates compared to AMI-VTA in ICD recipients at 3 years.

Funding Open Access funding enabled and organized by Projekt DEAL.

\section{Declarations}

Conflict of interest On behalf of all authors, the corresponding author states that there is no conflict of interest.

Open Access This article is licensed under a Creative Commons Attribution 4.0 International License, which permits use, sharing, adaptation, distribution and reproduction in any medium or format, as long as you give appropriate credit to the original author(s) and the source, provide a link to the Creative Commons licence, and indicate if changes were made. The images or other third party material in this article are included in the article's Creative Commons licence, unless indicated otherwise in a credit line to the material. If material is not included in the article's Creative Commons licence and your intended use is not permitted by statutory regulation or exceeds the permitted use, you will need to obtain permission directly from the copyright holder. To view a copy of this licence, visit http://creativecommons.org/licenses/by/4.0/.

\section{References}

1. Anyfantakis ZA, Baron G, Aubry P, Himbert D, Feldman LJ, Juliard JM, Ricard-Hibon A, Burnod A, Cokkinos DV, Steg PG (2009) Acute coronary angiographic findings in survivors of outof-hospital cardiac arrest. Am Heart J 157(2):312-318

2. Neumar RW, Nolan JP, Adrie C, Aibiki M, Berg RA, Bottiger BW, Callaway C, Clark RS, Geocadin RG, Jauch EC, Kern KB, Laurent I, Longstreth WT, Jr., Merchant RM, Morley P, Morrison LJ, Nadkarni V, Peberdy MA, Rivers EP, Rodriguez-Nunez A, Sellke FW, Spaulding C, Sunde K, Vanden Hoek T (2008) Post-cardiac arrest syndrome: epidemiology, pathophysiology, treatment, and prognostication. A consensus statement from the International Liaison Committee on Resuscitation (American Heart Association, Australian and New Zealand Council on Resuscitation, European Resuscitation Council, Heart and Stroke Foundation of Canada, InterAmerican Heart Foundation, Resuscitation Council of Asia, and the Resuscitation Council of Southern Africa); the American Heart Association Emergency Cardiovascular Care Committee; the Council on Cardiovascular Surgery and Anesthesia; the Council on Cardiopulmonary, Perioperative, and Critical Care; the Council on Clinical Cardiology; and the Stroke Council. Circulation 118(23):2452-2483.

3. Behnes M, Mashayekhi K, Weiss C, Nienaber C, Lang S, Reiser L, Bollow A, Taton G, Reichelt T, Ellguth D, Engelke N, Schupp T, Ansari U, El-Battrawy I, Rusnak J, Akin M, Borggrefe M, Akin I (2018) Prognostic impact of acute myocardial infarction in patients presenting with ventricular tachyarrhythmias and aborted cardiac arrest. J Am Heart Assoc 7(19):e010004

4. Di Diego JM, Antzelevitch C (2011) Ischemic ventricular arrhythmias: experimental models and their clinical relevance. Heart Rhythm 8(12):1963-1968
5. Cheema AN, Sheu K, Parker M, Kadish AH, Goldberger JJ (1998) Non-sustained ventricular tachycardia in the setting of acute myocardial infarction: tachycardia characteristics and their prognostic implications. Circulation 98(19):2030-2036

6. Al-Khatib SM, Stevenson WG, Ackerman MJ, Bryant WJ, Callans DJ, Curtis AB, Deal BJ, Dickfeld T, Field ME, Fonarow GC, Gillis AM, Hlatky MA, Granger CB, Hammill SC, Joglar JA, Kay GN, Matlock DD, Myerburg RJ, Page RL (2017) 2017 AHA/ ACC/HRS guideline for management of patients with ventricular arrhythmias and the prevention of sudden cardiac death: executive summary: a report of the American college of cardiology/American heart association task force on clinical practice guidelines and the heart rhythm society. Circulation 138(13):e210-e271

7. Kobayashi Y, Tanno K, Ueno A, Fukamizu S, Murata H, Watanabe N, Sasaki T, Yamamoto T, Takayama M, Nagao K (2018) In-hospital electrical storm in acute myocardial infarction- clinical background and mechanism of the electrical instability. Circ J 83(1):91-100

8. Priori SG, Blomstrom-Lundqvist C, Mazzanti A, Blom N, Borggrefe M, Camm J, Elliott PM, Fitzsimons D, Hatala R, Hindricks G, Kirchhof P, Kjeldsen K, Kuck KH, Hernandez-Madrid A, Nikolaou N, Norekval TM, Spaulding C, Van Veldhuisen DJ (2015) 2015 ESC Guidelines for the management of patients with ventricular arrhythmias and the prevention of sudden cardiac death: the Task Force for the Management of Patients with Ventricular Arrhythmias and the Prevention of Sudden Cardiac Death of the European Society of Cardiology (ESC). Endorsed by: Association for European Paediatric and Congenital Cardiology (AEPC). Eur Heart J 36(41):2793-2867

9. Pedersen CT, Kay GN, Kalman J, Borggrefe M, Della-Bella P, Dickfeld T, Dorian P, Huikuri H, Kim YH, Knight B, Marchlinski F, Ross D, Sacher F, Sapp J, Shivkumar K, Soejima K, Tada H, Alexander ME, Triedman JK, Yamada T, Kirchhof P, Lip GY, Kuck KH, Mont L, Haines D, Indik J, Dimarco J, Exner D, Iesaka Y, Savelieva I (2014) EHRA/HRS/APHRS expert consensus on ventricular arrhythmias. Heart Rhythm 11(10):e166-196

10. Israel CW, Barold SS (2007) Electrical storm in patients with an implanted defibrillator: a matter of definition. Ann Noninvasive Electrocardiol 12(4):375-382

11. Israel CW, Manegold JC (2014) Electrical storm: definition, prevalence, causes and prognostic implications. Herzschrittmacherther Elektrophysiol 25(2):59-65

12. Villacastin J, Almendral J, Arenal A, Albertos J, Ormaetxe J, Peinado R, Bueno H, Merino JL, Pastor A, Medina O, Tercedor L, Jimenez F, Delcan JL (1996) Incidence and clinical significance of multiple consecutive, appropriate, high-energy discharges in patients with implanted cardioverter-defibrillators. Circulation 93(4):753-762

13. Credner SC, Klingenheben T, Mauss O, Sticherling C, Hohnloser SH (1998) Electrical storm in patients with transvenous implantable cardioverter-defibrillators: incidence, management and prognostic implications. J Am Coll Cardiol 32(7):1909-1915

14. Verma A, Kilicaslan F, Marrouche NF, Minor S, Khan M, Wazni O, Burkhardt JD, Belden WA, Cummings JE, Abdul-Karim A, Saliba W, Schweikert RA, Tchou PJ, Martin DO, Natale A (2004) Prevalence, predictors, and mortality significance of the causative arrhythmia in patients with electrical storm. J Cardiovasc Electrophysiol 15(11):1265-1270

15. Thygesen K, Alpert JS, Jaffe AS, Chaitman BR, Bax JJ, Morrow DA, White HD (2019) Fourth universal definition of myocardial infarction (2018). Eur Heart J 40(3):237-269

16. Windecker S, Kolh P, Alfonso F, Collet JP, Cremer J, Falk V, Filippatos G, Hamm C, Head SJ, Juni P, Kappetein AP, Kastrati A, Knuuti J, Landmesser U, Laufer G, Neumann FJ, Richter DJ, Schauerte P, Sousa Uva M, Stefanini GG, Taggart DP, Torracca L, Valgimigli M, Wijns W, Witkowski A (2014) 2014 ESC/ 
EACTS Guidelines on myocardial revascularization: the task force on myocardial revascularization of the European society of cardiology (ESC) and the European Association for CardioThoracic Surgery (EACTS)developed with the special contribution of the European Association of Percutaneous Cardiovascular Interventions (EAPCI). Eur Heart J 35(37):2541-2619

17. Roffi M, Patrono C, Collet JP, Mueller C, Valgimigli M, Andreotti F, Bax JJ, Borger MA, Brotons C, Chew DP, Gencer B, Hasenfuss G, Kjeldsen K, Lancellotti P, Landmesser U, Mehilli J, Mukherjee D, Storey RF, Windecker S, Baumgartner $\mathrm{H}$, Gaemperli O, Achenbach S, Agewall S, Badimon L, Baigent C, Bueno H, Bugiardini R, Carerj S, Casselman F, Cuisset T, Erol C, Fitzsimons D, Halle M, Hamm C, Hildick-Smith D, Huber K, Iliodromitis E, James S, Lewis BS, Lip GY, Piepoli MF, Richter D, Rosemann T, Sechtem U, Steg PG, Vrints C, Luis Zamorano J (2016) 2015 ESC Guidelines for the management of acute coronary syndromes in patients presenting without persistent ST-segment elevation: task force for the management of acute coronary syndromes in patients presenting without persistent ST-segment elevation of the European Society of Cardiology (ESC). Eur Heart J 37(3):267-315

18. Steg PG, James SK, Atar D, Badano LP, Blomstrom-Lundqvist C, Borger MA, Di Mario C, Dickstein K, Ducrocq G, Fernandez-Aviles F, Gershlick AH, Giannuzzi P, Halvorsen S, Huber K, Juni P, Kastrati A, Knuuti J, Lenzen MJ, Mahaffey KW, Valgimigli M, van 'tHof, Widimsky, Zahger APD (2012) ESC Guidelines for the management of acute myocardial infarction in patients presenting with ST-segment elevation. Eur Heart J 33(20):2569-2619

19. Kip KE, Hollabaugh K, Marroquin OC, Williams DO (2008) The problem with composite end points in cardiovascular studies: the story of major adverse cardiac events and percutaneous coronary intervention. J Am Coll Cardiol 51(7):701-707

20. Pires LA, Lehmann MH, Steinman RT, Baga JJ, Schuger CD (1999) Sudden death in implantable cardioverter-defibrillator recipients: clinical context, arrhythmic events and device responses. J Am Coll Cardiol 33(1):24-32

21. Guerra F, Shkoza M, Scappini L, Flori M, Capucci A (2014) Role of electrical storm as a mortality and morbidity risk factor and its clinical predictors: a meta-analysis. Europace 16(3):347-353

22. Janse MJ, Wit AL (1989) Electrophysiological mechanisms of ventricular arrhythmias resulting from myocardial ischemia and infarction. Physiol Rev 69(4):1049-1169

23. Gorenek B, Blomstrom Lundqvist C, Brugada Terradellas J, Camm AJ, Hindricks G, Huber K, Kirchhof P, Kuck KH, Kudaiberdieva G, Lin T, Raviele A, Santini M, Tilz RR, Valgimigli M, Vos MA, Vrints C, Zeymer U, Lip GY, Potpara T, Fauchier L, Sticherling C, Roffi M, Widimsky P, Mehilli J, Lettino M, Schiele F, Sinnaeve P, Boriani G, Lane D, Savelieva I (2014) Cardiac arrhythmias in acute coronary syndromes: position paper from the joint EHRA, ACCA, and EAPCI task force. Europace 16(11):1655-1673
24. Pogwizd SM, Corr PB (1987) Electrophysiologic mechanisms underlying arrhythmias due to reperfusion of ischemic myocardium. Circulation 76(2):404-426

25. Sweeney MO, Sherfesee L, DeGroot PJ, Wathen MS, Wilkoff BL (2010) Differences in effects of electrical therapy type for ventricular arrhythmias on mortality in implantable cardioverterdefibrillator patients. Heart Rhythm 7(3):353-360

26. Runsio M, Bergfeldt L, Brodin LA, Ribeiro A, Samuelsson S, Rosenqvist M (1997) Left ventricular function after repeated episodes of ventricular fibrillation and defibrillation assessed by transoesophageal echocardiography. Eur Heart J 18(1):124-131

27. Bansch D, Bocker D, Brunn J, Weber M, Breithardt G, Block M (2000) Clusters of ventricular tachycardias signify impaired survival in patients with idiopathic dilated cardiomyopathy and implantable cardioverter defibrillators. J Am Coll Cardiol 36(2):566-573

28. Braam B, Joles JA, Danishwar AH, Gaillard CA (2014) Cardiorenal syndrome-current understanding and future perspectives. Nat Rev Nephrol 10(1):48-55

29. Damman K, Valente MA, Voors AA, O'Connor CM, van Veldhuisen DJ, Hillege HL (2014) Renal impairment, worsening renal function, and outcome in patients with heart failure: an updated meta-analysis. Eur Heart J 35(7):455-469

30. Carbucicchio C, Santamaria M, Trevisi N, Maccabelli G, Giraldi F, Fassini G, Riva S, Moltrasio M, Cireddu M, Veglia F, Della Bella P (2008) Catheter ablation for the treatment of electrical storm in patients with implantable cardioverter-defibrillators: short- and long-term outcomes in a prospective single-center study. Circulation 117(4):462-469

31. Deneke T, Shin DI, Lawo T, Bosche L, Balta O, Anders H, Bunz K, Horlitz M, Grewe PH, Lemke B, Mugge A (2011) Catheter ablation of electrical storm in a collaborative hospital network. Am J Cardiol 108(2):233-239

32. Kamibayashi T, Hayashi Y, Mammoto T, Yamatodani A, Taenaka N, Yoshiya I (1995) Thoracic epidural anesthesia attenuates halothane-induced myocardial sensitization to dysrhythmogenic effect of epinephrine in dogs. Anesthesiology 82(1):129-134

33. Schwartz PJ, Priori SG, Cerrone M, Spazzolini C, Odero A, Napolitano C, Bloise R, De Ferrari GM, Klersy C, Moss AJ, Zareba W, Robinson JL, Hall WJ, Brink PA, Toivonen L, Epstein AE, Li C, Hu D (2004) Left cardiac sympathetic denervation in the management of high-risk patients affected by the long-QT syndrome. Circulation 109(15):1826-1833

34. Ukena C, Mahfoud F, Ewen S, Bollmann A, Hindricks G, Hoffmann BA, Linz D, Musat D, Pavlicek V, Scholz E, Thomas D, Willems S, Bohm M, Steinberg JS (2016) Renal denervation for treatment of ventricular arrhythmias: data from an International Multicenter Registry. Clin Res Cardiol 105(10):873-879

Publisher's Note Springer Nature remains neutral with regard to jurisdictional claims in published maps and institutional affiliations. 